\title{
Progressive Familial Intrahepatic Cholestasis and its Subtypes: The First Report From Iran
}

\author{
Parnia Torfenejad, ${ }^{1}$ Bita Geramizadeh, ${ }^{1,2,}$ Mahmoud Haghighat, ${ }^{3}$ Seyed Mohsen Dahghani, ${ }^{3}$ Mojgan \\ Zahmatkeshan, ${ }^{3}$ Naser Honar, ${ }^{3}$ Mohammadhadi Imanieh, ${ }^{3}$ and Seyed Ali Malekhosseini ${ }^{4}$ \\ ${ }^{1}$ Department of Pathology, Shiraz University of Medical Sciences, Shiraz, IR Iran \\ ${ }^{2}$ Transplant Research Center, Shiraz University of Medical Sciences, Shiraz, IR Iran \\ ${ }^{3}$ Department of Pediatrics, Shiraz University of Medical Sciences, Shiraz, IR Iran \\ ${ }^{4}$ Department of Hepatobiliary Surgery, Shiraz University of Medical Sciences, Shiraz, IR Iran \\ "Corresponding author: Bita Geramizadeh, Department of Pathology, Shiraz University of Medical Sciences, Shiraz, IR Iran. Tel/Fax: +98-7136473238, E-mail: eramib@sums.ac.ir
}

Received 2016 April 20; Revised 2016 June 06; Accepted 2016 June 21.

\begin{abstract}
Background: Progressive familial intrahepatic cholestasis (PFIC) is a heterogeneous cholestatic disease (PFIC types 1, 2, and 3). Each type of the disease has different presentation, laboratory findings and prognosis. Up to now, there has been no report on the different types of this disease from Iran.

Objectives: In this study, we have tried to uncover the frequencies and clinicopathologic presentations of three types of PFIC over four years (2010 - 2014) in Namazi hospital, which is affiliated with the Shiraz University of Medical Sciences and is the main hepatobiliary center in Southern Iran.

Methods: During the above-mentioned four-year period, we studied 68 liver tissues taken from patients with a proven PFIC diagnosis, either in the form of a liver needle biopsy or explanted liver. Immunostaining was performed using three antibodies (ATP8B1, $\mathrm{ABCB11}$, and $\mathrm{ABCB} 4$ ) on liver sections. Hematoxylin and eosin-stained sections were also reviewed. All of the demographics, clinical and paraclinical data were retrieved from the patients' clinical charts.

Results: Among these 68 PFIC cases, the most common type of PFIC in our center was found to be type 2 (50\%), followed by type 1 (42.6\%), with type $3(7.4 \%$ ) representing the least common. Pruritis and jaundice have been identified as the most common symptoms in all three groups; however, patients with PFIC type 3 showed older age with higher GGT levels.

Conclusions: The two most common subtypes of PFIC in Iran are types 2 and 1, similar to some areas in the West. Immunostaining can accurately subclassify patients with PFIC.
\end{abstract}

Keywords: Progressive Familial Intrahepatic Cholestasos

\section{Background}

Progressive familial intrahepatic cholestasis (PFIC), also known as Byler disease, has been described as a group of childhood autosomal recessive disorders which present with hepatocellular cholestasis $(1,2)$. The disease was originally described in an Amish child who presented with recurrent bouts of jaundice, associated with light stools, dark urine and pruritis (3). It has been reported as a rare cause of childhood cholestasis and cirrhosis in Iran (4-6).

Three genotypes of PFIC have been described and associated with mutations in hepatocellular transport system genes (PFIC1, 2, 3) (2). PFIC1 is formed secondary to a mutation in ATP8B1 that codes an amino phospholipid transporter, PFIC2 is formed secondary to a mutation in ABCB11 that codes the bile salt export protein, and PFIC3 is caused by a mutation in the ABCB4 gene that codes the canalicular phospholipid export pump (MDR3). These genotypes have different clinical, biochemical and genetic characteristics.
Patients suffering from PFIC1 and 2 present in the neonatal period or early infancy, as it appears in the first months of life; meanwhile, PFIC3 may arise later in infancy, in childhood or even during young adulthood $(7,8)$.

Diagnosis is usually made by using a combined clinical, biochemical, radiological, histological and genetic approach, together with liver immunostaining and biliary lipid analysis $(9,10)$. Serum GGT (gamma glutamine transpeptidase) is normal in patients with PFIC1 and PFIC2, whereas those with PFIC3 have high serum GGT activity (11).

Electron microscopy of the bile in PFIC1 shows coarse and granular (Byler's) bile in comparison to PFIC2 and 3, which show amorphous bile (12-14).

Liver histologic studies are of considerable importance when evaluating a patient for PFIC since they allow for immunostaining to be performed. A number of commercially available MDR3 (multi-drug resistance 3) and BSEP (bile salt export pump) antibodies have been used (7, 8, 12). In immunohistochemistry studies, PFIC3 is associated 
with mild or absent canalicular staining with MDR3 (due to a mutation in the ABCB4 gene that codes the canalicular phospholipid export pump, MDR3), while PFIC2 shows similar findings with regard to BSEP antibodies (due to a mutation in $\mathrm{ABCB} 11$ that codes the bile salt export protein) (13).

Genetic testing involves DNA sequencing the 27 coding exons and their splice junctions. A resequencing chip, dedicated to looking for the genetic syndromes of cholestasis, has been developed and may facilitate diagnosis. As no phenotypic features can exclude PFIC1 or 2 in a patient with normal GGT PFIC, immunohistochemistry with BSEP staining followed by genetic analysis is recommended. In patients with negative BSEP staining, one should first test for $A B C B 11$, whereas in patients with normal BSEP staining, ATB8B1 mutation should be considered (12-14).

\section{Objectives}

To the best of our knowledge, there has yet to be a reported study classifying PFIC genotypes in Iran. In this four-year cross-sectional study (2010 - 2014), we aimed to determine and evaluate the PFIC genotypes in Iranian patients by using immunohistologic staining for 68 patients with confirmed PFIC.

\section{Methods}

The present study was designed as a cross-sectional analysis on the explanted livers and needle biopsy specimens of 68 patients with a confirmed PFIC diagnosis over a period of four years (June 2010 - June 2014) in Namazi hospital, which is affiliated with the Shiraz University of Medical Sciences and is the largest referral center of liver diseases in Southern Iran.

Baseline demographics, including patient age, gender, liver function tests and clinical symptoms, were collected from the clinical charts and recorded.

Paraffin-embedded blocks of explanted liver tissue and the liver biopsies of PFIC patients were extracted from the archives of pathology and immunostaining was performed based on standard immunohistochemical procedures to detect canalicular proteins.

IHC was performed by routine method, i.e., a 4 - $5 \mu \mathrm{m}$ section of the proper paraffin block was prepared for each case; then, after deparaffinization in xylol and hydration with $100 \%, 96 \%$ and $70 \%$ alcohol and washing steps with distilled water and phosphate buffer saline (PBS) and adding $\mathrm{H}_{2} \mathrm{O}_{2}$, antigen retrieval was performed. Overnight, secondary antibodies were applied and counterstaining with hematoxylin was the final step.
The following antibodies were used: anti-ATP8B1 and CD10, in order to investigate PFIC1, anti-ABCB11 (anti-BSEP) for PFIC type 2, and anti-ABCB4 (MDR3 protein) for PFIC type 3. Table 1 shows the characteristics of the antibodies. Immunostaining was classified as positive (when bile canaliculi were stained) and negative (when bile canaliculi were not stained).

Normal liver tissue staining with the above antibodies was considered the positive control for all three types.

\section{Results}

Sixty-eight patients with a confirmed PFIC diagnosis were investigated by immunostaining. Forty-three (63.2\%) of the cases were male and the remaining twenty-five cases (36.8\%) were female.

Among these 68 specimens, 18 (26.5\%) were liver biopsies and 50 (73.5\%) specimens were explanted livers.

The baseline clinical and biochemical characteristics of the studied patients are shown in Table 2.

The majority $(\mathrm{n}=34)$ of cases were PFIC type $2(50 \%)$ and 29 cases were type $1(42.6 \%)$. The rest of the cases $(n=5,7.4 \%)$ were categorized as type 3 . The most common presenting symptoms were jaundice (82.4\%) and pruritis (48.5\%) followed by vomiting (7.4\%) and bleeding tendency (4.45\%).

\subsection{PFIC Type 1}

Twenty-nine (42.6\%) cases had normal IHC studies using anti-ABCB4 and anti-ABCB11 antibodies and abnormal (not stained) ATP8B1 and CD10 antibodies which was in favor of PFIC type 1(Figure 1). Seventeen patients (58.6\%) were male and twelve patients (41.4\%) were female. Tables 3 and 4 summarize the baseline characteristics of PFIC type 1 patients.

\subsection{PFIC Type 2}

Absence of canalicular immunostaining with antiABCB11 antibody was evident in 34 (50\%) cases (Figure 2). Twenty-two (64.7\%) patients were male and twelve (35.3\%) patients were female. Tables 5 and 6 summarize the baseline characteristics of patients with PFIC type 2.

\subsection{PFIC Type 3}

Five (7.4\%) patients were categorized as type 3 , all of which were discovered in cirrhotic explanted livers (Figure 3). Four ( $80 \%$ ) of the cases were male and one case (20\%) was female. No type 3 cases were found in patients less than one year of age. The demographics, symptoms, clinical findings and biochemical data for a total of five patients with PFIC 3 are summarized in Tables 7 and 8. 
Table 1. Characteristics of Different Antibodies Used in the Patients with PFIC for Subtyping

\begin{tabular}{lccc}
\hline Antibody & Company & Dilution & Antigen Retrieval \\
\hline ATP8B1 & Abcam & $1 / 200$ & Tris-EDTA \\
ABCB11 & Abcam & $1 / 500$ & Tris-EDTA \\
ABCB4 & Abcam & $1 / 200$ & Tris-EDTA \\
\hline
\end{tabular}

Table 2. Clinical and Biochemical Characteristics of PFIC Patients ${ }^{\mathrm{a}}$

\begin{tabular}{lcc}
\hline Variables & Mean \pm SD & Minimum-Maximum \\
\hline Age, $\mathbf{y}$ & $4.8 \pm 4.5$ & 3 months - 19 years \\
\hline GGT Level, IU/L & $94.9 \pm 143.2$ & $6-350$ \\
\hline AST, IU/L & $163.3 \pm 237$ & $28-1050$ \\
\hline ALT IU/L & $177.7 \pm 293$ & $13-1440$ \\
\hline Total Bilirubin, $\mathbf{~ g / d L ~}$ & $6.9 \pm 10.8$ & $30-60.50$ \\
\hline Direct Bilirubin, $\mathbf{~ m g / d L ~}$ & $3.2 \pm 4.5$ & $10-21.60$ \\
\hline Total Protein, $\mathbf{g} / \mathbf{d L}$ & $6.5 \pm 1.4$ & $2.5-10$ \\
\hline Serum Albumin, $\mathbf{g} / \mathbf{d L}$ & $3.6 \pm 0.5$ & $2.1-4.7$ \\
\hline
\end{tabular}

${ }^{\mathrm{a}}$ Normal levels: ALT < $40 \mathrm{IU} / \mathrm{L}$, AST normal $<40 \mathrm{IU} / \mathrm{L}, \mathrm{GGT}<45 \mathrm{IU} / \mathrm{L}$.
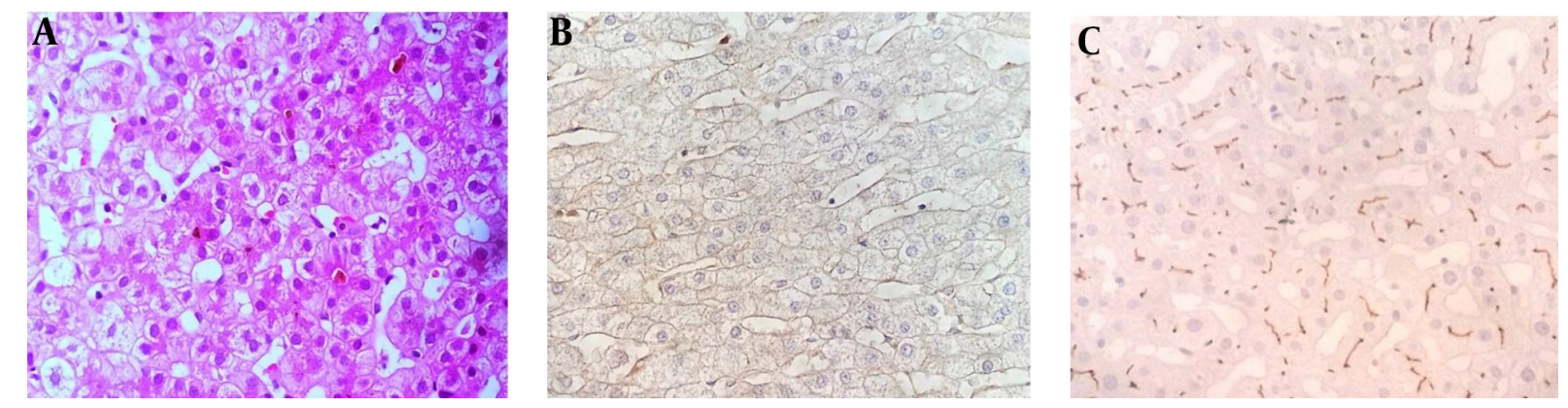

Figure 1. A, Section shows many cholestatic rosettes in a patient with PFIC-1(H\&EX250);B, PFIC1 immunostaining with ATP8B1 with negative results; C, Normal liver with intact staining with ATP8B1.

\section{Discussion}

Progressive familial intrahepatic cholestatic (PFIC) disease constitutes between $10 \%-15 \%$ of the causes of cholestasis in pediatric patients and this disease is the cause of $10 \%$ $-15 \%$ of liver transplants (15). It should be accurately differentiated from other cholestatic liver disorders in children because of the differences in its prognosis and treatment (7).

PFIC typing is also important as the course of the disease, some clinical and extrahepatic manifestations and paraclinical tests differ according to the three types of the disease (7).

Immunohistochemical study is a helpful method to di- agnose and classify the disease $(10,12,14-16)$; however, there has not yet been such a study regarding the classification of the patients with PFIC in the Iranian population.

As indicated in the previous studies, there are three different antibodies used in the IHC method to type the PFIC disease: anti-ATP8B1 and anti-CD10 are used for type 1, antiBSEP (ABCB11) is used for type 2 and anti-MDR3 (ABCB4) is used for type 3 of the disease $(10,12,14-20)$.

A powerful correlation has been described between the antibodies detecting the ultimate product of each type of the disease with specific mutations $(10,12,14-16,19)$.

In our population, the most frequent types were type 2 (50\%) and type 1 (42.6\%), with only five (7.4\%) of the cases being considered type 3 . These results are compatible with 
Table 3. Main Characteristics of 29 PFIC1 Patients ${ }^{\mathrm{a}}$

\begin{tabular}{lcc}
\hline Variables & Mean \pm SD & Minimum-Maximum \\
\hline Age years & $5.1 \pm 4.8$ & 3 months - 18 years \\
\hline GGT Level & $112.6 \pm 16.5$ & $9-74$ \\
\hline AST, $\mathbf{U} / \mathbf{L}$ & $168.2 \pm 228.2$ & $28-940$ \\
\hline ALT, $\mathbf{U} / \mathbf{L}$ & $167.9 \pm 289.1$ & $13-1350$ \\
\hline Total bilirubin, $\mathbf{m g} / \mathbf{d L}$ & $6.5 \pm 8.8$ & $0.3-43.0$ \\
\hline Direct bilirubin, $\mathbf{m g} / \mathbf{d L}$ & $3.1 \pm 3.8$ & $0.1-17.3$ \\
\hline Serum albumin, $\mathbf{g} / \mathbf{d L}$ & $3.6 \pm 0.5$ & $2.5-4.6$ \\
\hline Total protein, $\mathbf{g} / \mathbf{d L}$ & $6.4 \pm 1.5$ & $2.8-10.0$ \\
\hline
\end{tabular}

${ }^{\text {a }}$ Normal levels: ALT < 40 IU/L, AST normal < 40IU/L, GGT < 45IU/L.

Table 4. Presenting Symptoms of 29 PFIC1 Patients

\begin{tabular}{lr}
\hline Presenting Symptoms & No. (\%) \\
\hline Jaundice & $24(82.8)$ \\
\hline Pruritis & $14(48.3)$ \\
\hline Bleeding tendency & $1(3.4)$ \\
\hline Vomiting & $2(6.9)$ \\
\hline Poor feeding & $2(6.9)$ \\
\hline
\end{tabular}
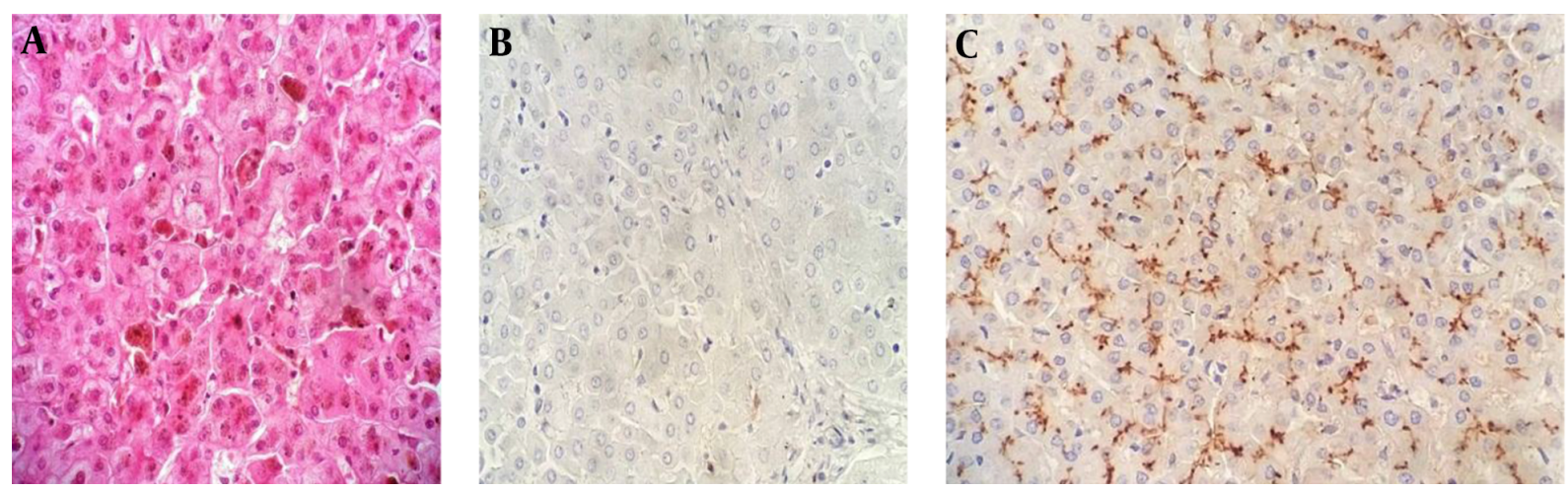

Figure 2. A, Section from liver shows cholestatic rosettes and ballooning degeneration and a few multinucleated hepatocytes (H\&EX250); B, Section from PFIC-2 that is negative with $A B C B 11 ; C$, Section from normal liver immunostained with $A B C B 11$.

the results of the previous literature that studied the three types simultaneously. For instance, Giovannoni et al. (21) studied 27 Italian patients, both by gene study and immunohistochemistry, and found that type 2 of the disease is the most frequent ( 17 patients $=63 \%$ ), followed by type $1(7=26 \%)$ and type $3(3=11 \%)$. In 62 French patients studied by Davit-Spraul, 39 (63\%) cases were type 2,13 (21\%) cases were type 1 and 10 (16\%) of the cases were categorized as unknown (8).
Many of the authors of past studies have concentrated on only one type of the disease, while more recent studies have shown different methods for subtyping all 3 types of PFIC. Table 9 shows the results of different studies from several countries regarding the frequencies of different types of PFIC using either gene studies or immunohistochemistry. According to the clinical presentation, all three types generally presented with jaundice and pruritis; however, GGT levels were higher in type 3, which aligns with previ- 
Table 5. Main Characteristics of 34 PFIC2 Patients ${ }^{\mathrm{a}}$

\begin{tabular}{lcc}
\hline Variables & Mean \pm SD & Minimum-Maximum \\
\hline Age, $\mathbf{y}$ & $4.4 \pm 4.7$ & 7 months - 19 years \\
GGT, IU/L & $68.1 \pm 11.8$ & $6.0-60$ \\
\hline AST, IU/L & $152.1 \pm 257.7$ & $36.0-1050.0$ \\
ALT, IU/L & $165.1 \pm 307.8$ & $17-1440$ \\
\hline Total Bilirubin, $\mathbf{m g} / \mathbf{d L}$ & $7.6 \pm 13.1$ & $0.3-60.5$ \\
\hline Direct Bilirubin, $\mathbf{m g} / \mathbf{d L}$ & $3.5 \pm 5.2$ & $0.1-21.6$ \\
\hline Serum Albumin, $\mathbf{g} / \mathbf{d L}$ & $3.7 \pm 0.6$ & $2.1-4.7$ \\
\hline Total Protein, $\mathbf{g} / \mathbf{d L}$ & $6.6 \pm 1.3$ & $2.5-8.9$ \\
\hline
\end{tabular}

${ }^{\text {a }}$ Normal levels: ALT < 40 IU/L, AST normal $<40$ IU $/$ L, GGT $<45$ IU/L.

Table 6. Presenting Symptoms of 34 PFIC2 Patients

\begin{tabular}{|c|c|}
\hline Presenting Symptom & No. (\%) \\
\hline Jaundice & $27(79.4)$ \\
\hline Pruritis & $18(52.9)$ \\
\hline Bleeding tendency & $1(2.9)$ \\
\hline Vomiting & $2(5.9)$ \\
\hline
\end{tabular}
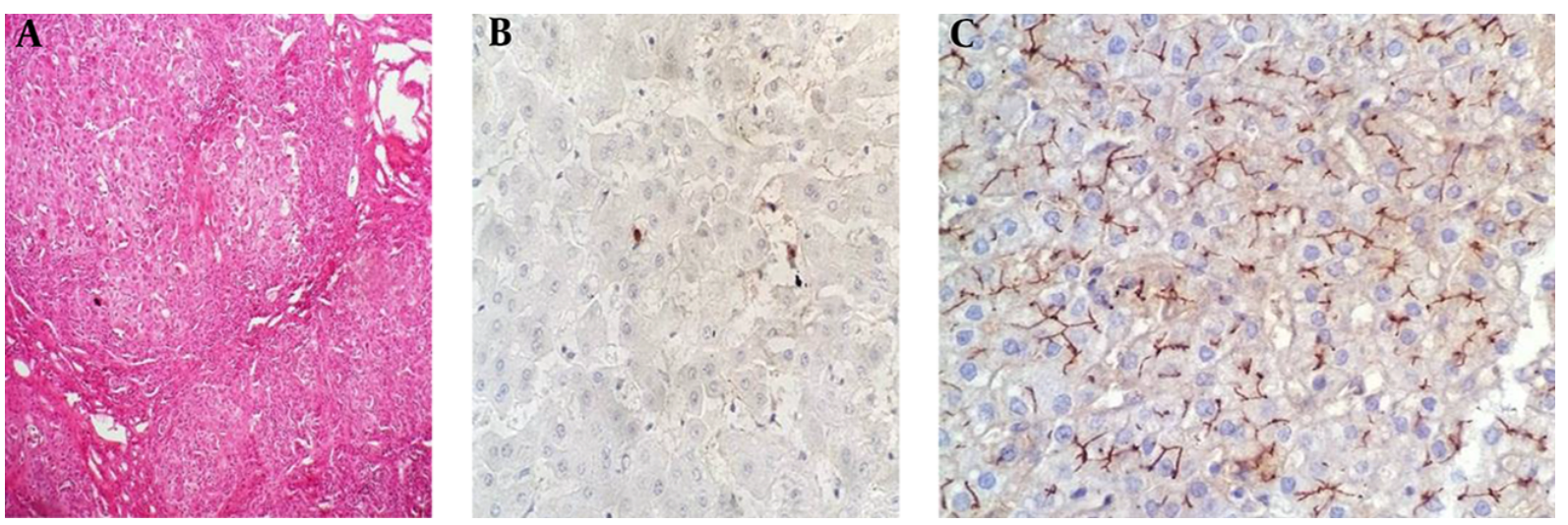

Figure 3. A, Section from cirrhotic explanted liver with PFIC-3 showing severe fibrosis, cholestatic rosettes and ductular reaction (H\&EX100); B, Sections from PFIC-3 negative for $\mathrm{ABCB} 4$; C, Section from normal liver with intact ABCB4.

ous reports (8).

\subsection{Conclusions}

PFIC can be accurately typed by IHC studies. In our center, we found type 2 to be the most common, followed by types 1 and 3 . This is similar to the frequencies reported in the West. 
Table 7. Main Characteristics of five Cases of PFIC Type $3^{a}$

\begin{tabular}{lcc}
\hline Variables & Mean $\pm \mathbf{S D}$ & Minimum-Maximum \\
\hline Age $\mathbf{y}$ & $6.2 \pm 1.3$ & $4-7$ years \\
\hline GGT Level, IU/L & $179.0 \pm 153.2$ & $19-350$ \\
\hline AST, IU/L & $211.2 \pm 170.2$ & $35-479$ \\
\hline ALT, IU/L & $317.2 \pm 224.9$ & $33-514$ \\
\hline Total Bilirubin, $\mathbf{~ m g / d L ~}$ & $4.1 \pm 4.2$ & $0.4-10.6$ \\
\hline Direct Bilirubin, $\mathbf{~ m g / d L ~}$ & $2.5 \pm 2.8$ & $0.1-7.1$ \\
\hline Serum Albumin, $\mathbf{g} / \mathbf{d L}$ & $3.6 \pm 0.6$ & $3.0-4.5$ \\
\hline Total Protein, $\mathbf{g} / \mathbf{d L}$ & $6.2 \pm 0.7$ & $5.4-6.9$ \\
\hline
\end{tabular}

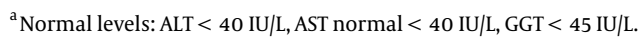

Table 8. Presenting Symptoms of Five Cases of PFIC3

\begin{tabular}{lc}
\hline Presenting Symptom & No. (\%) \\
\hline Jaundice & $5(100.0)$ \\
Pruritis & $1(20.0)$ \\
Bleeding Tendency & $1(20.0)$ \\
Vomiting & $1(20.0)$ \\
\hline
\end{tabular}

Table 9. Percentage of PFIC Types in Different Countries using Different Methods

\begin{tabular}{|c|c|c|c|c|c|c|c|}
\hline Author & Country & Year & Method of Typing & Total Patients & Type 1 No. (\%) & Type 2 No. (\%) & Type 3 No. (\%) \\
\hline Giovannoni I et al. (21) & Italy & 2015 & IHC/Gene study & 27 & $7(26)$ & $17(63)$ & $3(11)$ \\
\hline Davit-Spraul et al. (8) & France & 2010 & IHC/Gene study & 62 & $13(21)$ & $39(63)$ & \\
\hline Klomp et al. (22) & Netherlands & 2004 & Gene study & 180 & $54(30)$ & & \\
\hline Evason et al. (16) & USA & 2011 & IHC/Gene study & 12 & & $10(83)$ & \\
\hline Strautnieks et al. (12) & England & 2008 & & 88 & & $82(93)$ & \\
\hline Chen et al. (23) & Taiwan & 2008 & IHC/HPLC/SEQUENCIG & 18 & & $4(25)$ & \\
\hline Chen et al. (24) & Taiwan & 2001 & Gene study & 47 & & & $1(2)$ \\
\hline Colombo et al. (25) & Italy & 2011 & Gene study & 133 & & & $44(33)$ \\
\hline Jacquemi et al. (10) & France & 2001 & IHC/Gene study & 12 & & & $9(75)$ \\
\hline El-Guindi et al. (26) & Egypt & 2016 & $\mathrm{IHC}$ & 25 & $2(8)$ & $17(68)$ & $6(24)$ \\
\hline Our study & Iran & 2016 & $\mathrm{IHC}$ & 68 & $29(42.6)$ & $34(50)$ & $5(7.4)$ \\
\hline
\end{tabular}

\section{Footnote}

Authors' Contribution: Parnia Torfenejad: collecting the cases; Bita Geramizadeh: project concept; Mahmoud Haghighat: gathering the cases; Seyed Mohsen Dahghani: gathering the cases; Mojgan Zahmatkeshan: gathering the cases; Naser Honar: gathering the cases; Mohammadhadi Imanieh: gathering the cases; Seyed Ali Malekhosseini: gathering the cases.

\section{References}

1. Jacquemin E, Dumont M, Bernard O, Erlinger S, Hadchouel M. Evidence for defective primary bile acid secretion in children with progressive familial intrahepatic cholestasis (Byler disease). Eur J Pediatr. 1994;153(6):424-8. [PubMed: 8088298].

2. Jacquemin E. Progressive familial intrahepatic cholestasis. Genetic basis and treatment. Clin Liver Dis. 2000;4(4):753-63. [PubMed: 11232355]. 
3. Jacquemin E. Progressive familial intrahepatic cholestasis. Clin Res Hepatol Gastroenterol. 2012;36 Suppl 1:26-35. doi: 10.1016/S22107401(12)70018-9. [PubMed: 23141890].

4. Dehghani SM, Imanieh MH, Haghighat M, Malekpour A, Falizkar Z. Etiology and complications of liver cirrhosis in children:report of a single center from southern iran. Middle East J Dig Dis. 2013;5(1):41-6. [PubMed: 24829669].

5. Monajemzadeh M, Tabriz HM, Mahjoub F, Fallahi G, Farahmand F. Liver needle biopsy in Iraninan pediatric patients: diagnostic significance and pattern of liver diseases. Indian J Pathol Microbiol. 2009;52(1):10-3. [PubMed: 19136770].

6. Talachian E, Bidari A, Mehrazma M, Nick-khah N. Biopsy-driven diagnosis in infants with cholestatic jaundice in Iran. World JGastroenterol. 2014;20(4):1048-53. doi: 10.3748/wjg.v20.i4.1048. [PubMed: 24574777].

7. Davit-Spraul A, Gonzales E, Baussan C, Jacquemin E. Progressive familial intrahepatic cholestasis. Orphanet J Rare Dis. 2009;4:1. doi: 10.1186/1750-1172-4-1. [PubMed: 19133130].

8. Davit-Spraul A, Fabre M, Branchereau S, Baussan C, Gonzales E, Stieger B, et al. ATP8B1 and ABCB11 analysis in 62 children with normal gamma-glutamyl transferase progressive familial intrahepatic cholestasis (PFIC): phenotypic differences between PFIC1 and PFIC2 and natural history. Hepatology. 2010;51(5):1645-55. doi: 10.1002/hep.23539. [PubMed: 20232290].

9. Gonzales E, Gerhardt MF, Fabre M, Setchell KD, Davit-Spraul A, Vincent I, et al. Oral cholic acid for hereditary defects of primary bile acid synthesis: a safe and effective long-term therapy. Gastroenterology. 2009;137(4):1310-20. doi: 10.1053/j.gastro.2009.07.043. [PubMed: 19622360].

10. Jacquemin E, De Vree JM, Cresteil D, Sokal EM, Sturm E, Dumont $\mathrm{M}$, et al. The wide spectrum of multidrug resistance 3 deficiency: from neonatal cholestasis to cirrhosis of adulthood. Gastroenterology. 2001;120(6):1448-58. [PubMed: 11313315].

11. Maggiore G, Bernard O, Riely CA, Hadchouel M, Lemonnier A, Alagille D. Normal serum gamma-glutamyl-transpeptidase activity identifies groups of infants with idiopathic cholestasis with poor prognosis. $J$ Pediatr. 1987;111(2):251-2. [PubMed: 2886574].

12. Strautnieks SS, Byrne JA, Pawlikowska L, Cebecauerova D, Rayner A, Dutton L, et al. Severe bile salt export pump deficiency: 82 different ABCB11 mutations in 109 families. Gastroenterology. 2008;134(4):120314. doi: 10.1053/j.gastro.2008.01.038. [PubMed: 18395098].

13. Stapelbroek JM, van Erpecum KJ, Klomp LW, Houwen RH. Liver disease associated with canalicular transport defects: current and future therapies. J Hepatol. 2010;52(2):258-71. doi: 10.1016/j.jhep.2009.11.012. [PubMed: 20034695].

14. de Vree JM, Jacquemin E, Sturm E, Cresteil D, Bosma PJ, Aten J, et al. Mutations in the MDR3 gene cause progressive familial intrahepatic cholestasis. Proc Natl Acad Sci U S A. 1998;95(1):282-7. [PubMed: 9419367].

15. Mousavi SA, Karami H. Partial internal biliary diversion in progressive familial intrahepatic cholestasis: introduction of a new approach. Hepat Mon. 2014;14(3):13549. doi: 10.5812/hepatmon.13549. [PubMed:
24693315]

16. Evason K, Bove KE, Finegold MJ, Knisely AS, Rhee S, Rosenthal $\mathrm{P}$, et al. Morphologic findings in progressive familial intrahepatic cholestasis 2 (PFIC2): correlation with genetic and immunohistochemical studies. Am J Surg Pathol. 2011;35(5):687-96. doi: 10.1097/PAS.ob013e318212ec87. [PubMed: 21490445].

17. Paulusma CC, Groen A, Kunne C, Ho-Mok KS, Spijkerboer AL, Rudi de Waart D, et al. Atp8b1 deficiency in mice reduces resistance of the canalicular membrane to hydrophobic bile salts and impairs bile salt transport. Hepatology. 2006;44(1):195-204. doi: 10.1002/hep.21212. [PubMed: 16799980].

18. Eppens EF, van Mil SW, de Vree JM, Mok KS, Juijn JA, Oude Elferink RP, et al. FIC1, the protein affected in two forms of hereditary cholestasis, is localized in the cholangiocyte and the canalicular membrane of the hepatocyte. J Hepatol. 2001;35(4):436-43. [PubMed: 11682026].

19. Jansen PL, Strautnieks SS, Jacquemin E, Hadchouel M, Sokal EM, Hooiveld GJ, et al. Hepatocanalicular bile salt export pump deficiency in patients with progressive familial intrahepatic cholestasis. Gastroenterology. 1999;117(6):1370-9. [PubMed: 10579978].

20. Giovannoni I, Santorelli FM, Candusso M, Di Rocco M, Bellacchio E, Callea F, et al. Two novel mutations in African and Asian children with progressive familial intrahepatic cholestasis type 3. Dig Liver Dis. 2011;43(7):567-70. doi: 10.1016/j.dld.2011.03.004. [PubMed: 21514256].

21. Giovannoni I, Callea F, Bellacchio E, Torre G, De Ville De Goyet J, Francalanci P. Genetics and Molecular Modeling of New Mutations of Familial Intrahepatic Cholestasis in a Single Italian Center. PLoS One. 2015;10(12):0145021. doi: 10.1371/journal.pone.0145021. [PubMed: 26678486].

22. Klomp LW, Vargas JC, van Mil SW, Pawlikowska L, Strautnieks SS, van Eijk MJ, et al. Characterization of mutations in ATP8B1 associated with hereditary cholestasis. Hepatology. 2004;40(1):27-38. doi: 10.1002/hep.20285. [PubMed: 15239083]

23. Chen HL, Liu YJ, Su YN, Wang NY, Wu SH, Ni YH, et al. Diagnosis of BSEP/ABCB11 mutations in Asian patients with cholestasis using denaturing high performance liquid chromatography. J Pediatr. 2008;153(6):825-32. doi: 10.1016/j.jpeds.2008.06.034. [PubMed: 18692205].

24. Chen HL, Chang PS, Hsu HC, Lee JH, Ni YH, Hsu HY, et al. Progressive familial intrahepatic cholestasis with high gammaglutamyltranspeptidase levels in Taiwanese infants: role of MDR3 gene defect?. Pediatr Res. 2001;50(1):50-5. doi: 10.1203/00006450200107000-00011. [PubMed: 11420418].

25. Colombo C, Vajro P, Degiorgio D, Coviello DA, Costantino L, Tornillo L, et al. Clinical features and genotype-phenotype correlations in children with progressive familial intrahepatic cholestasis type 3 related to ABCB4 mutations. J Pediatr Gastroenterol Nutr. 2011;52(1):73-83. doi: 10.1097/MPG.0b013e3181f50363. [PubMed: 21119540].

26. El-Guindi MA, Sira MM, Hussein MH, Ehsan NA, Elsheikh NM. Hepatic immunohistochemistry of bile transporters in progressive familial intrahepatic cholestasis. Ann Hepatol. 2016;15(2):222-9. doi: 10.5604/16652681.1193718. [PubMed: 26845599]. 